\title{
Development of the anti-cancer food scoring system 2.0: Validation and nutritional analyses of quantitative anti-cancer food scoring model
}

\author{
Yeo-Jin Hong', Jeongseon Kim ${ }^{2}$, Hye Yoon Lee ${ }^{3}$ and Chai Hong $\mathrm{Rim}^{45}$ \\ 'Department of Nutrition, Yonsei University, Seoul 03722, Korea \\ ${ }^{2}$ Department of Cancer Biomedical Science, Graduate School of Cancer Science and Policy, National Cancer Center, Gyeonggi 10408, Korea \\ ${ }^{3}$ Department of Surgery, Korea University Medical College, Seoul 02841, Korea. \\ ${ }^{4}$ Department of Radiation Oncology, Korea University Medical College and Korea University Ansan hospital, Gyeonggi 15355, Korea
}

BACKGROUND/OBJECTIVE: We have previously designed the anti-cancer food scoring model (ACFS) 1.0, an evidence-based quantitative tool analyzing the anti-cancer or carcinogenic potential of diets. Analysis was performed using simple quantitative indexes divided into 6 categories (S, A, B, C, D, and E). In this study, we applied this scoring model to wider recipes and evaluated its nutritional relevance.

MATERIALS/METHODS: National or known regional databases were searched for recipes from 6 categories: Korean out-dining, Korean home-dining, Western, Chinese, Mediterranean, and vegetarian. These recipes were scored using the ACFS formula and the nutrition profiles were analyzed.

RESULTS: Eighty-eight international recipes were analyzed. All S-graded recipes were from vegetarian or Mediterranean categories. The median code values of each category were B (Korean home-dining), C (Korean out-dining), B (Chinese), A (Mediterranean), $S$ (vegetarian), and D (Western). The following profiles were correlated $(P<0.05)$ with ACFS grades in the univariate trend analysis: total calories, total fat, animal fat, animal protein, total protein, vitamin $D$, riboflavin, niacin, vitamin $B_{12}$, pantothenic acid, sodium, animal iron, zinc, selenium, and cholesterol (negative trends), and carbohydrate rate, fiber, water-soluble fiber, vitamin $\mathrm{K}$, vitamin $\mathrm{C}$, and plant calcium (positive trends). Multivariate analysis revealed that animal fat, animal iron, and niacin (negative trends) and animal protein, fiber, and vitamin $C$ (positive trends) were statistically significant. Pantothenic acid and sodium showed non-significant negative trends $(P<0.1)$, and vitamin $B_{12}$ showed a non-significant positive trend.

CONCLUSION: This study provided a nutritional basis and extended the utility of ACFS, which is a bridgehead for future cancer-preventive clinical trials using ACFS.

Nutrition Research and Practice 2020;14(1):32-44; https://doi.org/10.4162/nrp.2020.14.1.32; pISSN 1976-1457 elSSN 2005-6168

Keywords: Cancer, prevention, food, diet, scoring model

\section{INTRODUCTION}

Cancer is a non-communicable disease and is the leading cause of death globally [1]. In the United States, it is the second leading cause of death, following cardiovascular diseases. In Korea and Japan, it is the first leading cause of death [2-4]. Causes of cancer vary widely and many remain unknown; however, the most significant known causes are smoking and diet [5]. Doll and Peto previously estimated that each of these 2 causes accounted for about one-third of cancer causes [6]. In a recent large prospective study, cancer-specific mortality was found to be reduced to $61 \%$ in a population that adhered to the cancer prevention recommendations by the World Cancer Research Fund (WCRF) and the American Institute for Cancer
Research (AICR) [7], aligning with the estimates of the research conducted by Doll and Peto.

The method of controlling the risk factor for smoking is simply cessation. However, identifying the foods beneficial for cancer prevention and those that are carcinogenic is more complex. A variety of studies on the relationship between cancer and food, from laboratory to large-scale population studies, have been published [8-11]. However, the results of these studies were diverse, and the studies differed from each other in terms of design; moreover, large differences were found according to region and culture. Furthermore, commercial information with inadequate scientific evidence has been widespread and has led to confusion in the general population.

Food is consumed daily by everyone in every socioeconomic

\footnotetext{
This study is supported by the National Research Fund of Korea (NRF-2018R1D1A1B07046998).

${ }^{\S}$ Corresponding Author: Chai Hong Rim, Tel. 82-31-412-6850, Fax. 82-31-412-6851, Email. crusion3@naver.com

Received: May 10, 2019, Revised: June 4, 2019, Accepted: July 23, 2019

This is an Open Access article distributed under the terms of the Creative Commons Attribution Non-Commercial License (http://creativecommons.org/licenses/by-nc/3.0/) which permits unrestricted non-commercial use, distribution, and reproduction in any medium, provided the original work is properly cited.
} 
class. Obtaining evidence-based information about foods that can prevent cancer among people without nutritional and medical expertise is difficult. Therefore, establishing an intuitive anti-cancer or carcinogenic food index is very useful in promoting cancer-related health.

Based on these needs, we developed the anti-cancer food scoring model (ACFS) 1.0 [12]. The ACFS 1.0 model assigned points to 22 food elements using a systematic method based on literature evaluation. The points were added up based on composition ratios, and unhealthy cooking methods (high salt or oil) were taken into account, to arrive at any of the 6 anticancer grades. This model has the advantage of easy-tounderstand points and grades, integrating a vast amount of information from the literature.

This study aimed to apply the previously constructed ACFS algorithm to various international recipes, including Mediterranean, vegetarian, Chinese, Western, and Korean diets, and to verify the nutritional validity of the model using a computeraided nutrition analysis based on the obtained information.

\section{MATERIALS AND METHODS}

\section{Calculation model of ACFS}

Here, we introduce the calculation model of ACFS briefly, as described in more detail in our previous article [12]. First, we set the 22 ACFS food element codes that are diverse enough to evaluate the majority of Western and Asian recipes. They include whole grain (WG), red meat (RM), green leafy salad (GLS), fish (FISH), garlic (Ga), soy food (SF), cruciferous vegetable $(\mathrm{CV})$, allium vegetable $(\mathrm{AV})$, cheese $(\mathrm{Ch})$, seaweed $(\mathrm{SW})$, fruit (FR), non-starchy vegetable (NSV), white meat (WM), carotene-rich vegetable (CRV), processed meat (PM), selenium-rich food (SRF), milk (Mi), egg (Egg), refined grain (RG), legume (Le), chili (Chili), and potato (Pot).

For each code, studies on 5 major cancers (i.e., breast, colorectal, stomach, lung, and liver) with high global mortality and affected by diets were analyzed. Literature evaluation was based on the 2nd expert report of WCRF/AICR [13]. In the 2nd expert report of WCRF/AICR, the level of evidence was classified into 4 stages (convincing, probable, limited-suggestive, and limited-no conclusion). Level of evidence was determined by the number of cohort or case-control studies, quality of the studies, heterogeneity among the studies, and biological plausibility. In ACFS, code grade $A$ is allotted for convincing or probable, code grade B for limited-suggestive, and code grade $C$ for limited-no conclusion. Then, 10, 5, and 2 points were assigned to code grades A, B and C, respectively. Assigned code points according to each of the 5 cancers, defined as "cancer specific grades", were summed to yield "ACFS code grades" from $A$ to $E$.

The meals analyzed were divided into constituent components and matched with the ACFS codes. The "ingredient score" was calculated by multiplying the ratio (using food exchange unit, FEU) of each component in the meal with the code grade point (A, B, C, D, and E correspond to 5,4,3,2,1 points respectively). FEU was used instead of the weight of the ingredient because of its similarity to serving size, which was the more commonly used measurement than weight in reference studies $[12,50]$.
FEUs for Korean and Chinese recipes were based on the Korean Diabetes Food Exchange Table. FEUs for Western, vegetarian, and Mediterranean recipes were calculated from the American Dietetic Association Food Exchange Table. The grade level, out of 5 grade levels, was determined from the ingredient scores and the meal was downgraded 1 level if it was cooked using an unhealthy method ( $>2 \mathrm{~g}$ of salt or $>20 \mathrm{~g}$ of oil used in cooking). The final grade was named as the ACFS grade and was interpreted as follows:

Grade S, ideal for cancer prevention

Grade A, good for cancer prevention

Grade B, might have anticancer potential

Grade $C$, difficult to be regarded as preventive or carcinogenic

Grade D, might be against cancer prevention

Grade $E$, probably against cancer prevention.

In Table 1, we have presented the process of calculating the ACFS grade of six sample meals, belonging to six dietary patterns. The calculation algorithm is schematically described in Fig. 1.

\section{Selection of recipes and nutritional analyses}

For Chinese recipes, we searched for 'Representative Chinese cuisine' in the People's Network (kr.people.com.cn) and obtained the ingredient information from the websites (https://www.allre cipes.com/, http://cookingsimplechinesefoodathome.com/, http: //www.people.com.cn/, all accessed between August 10 and 17, 2018) for the top 10 meals. For 20 Mediterranean and 10 vegetarian meals, commonly considered as healthy diets, the recipes were obtained from "The New Mayo Clinic Cookbook" [14]. For 18 Western meals, we selected the commonly consumed routine daily life meals and obtained the recipes from the following cooking portals, referring to author discussions (https://www.mrbreakfast.com/, https://www.tasteofhome.com/, https://www.seriouseats.com/, all accessed between August 10 and 17, 2018). Fifteen Korean home-dining and 15 Korean outdining meals were chosen from the frequently consumed meals in the 7th Korea National Health and Nutrition Examination Survey (KNHANES VII-1), 2016, 24-hour dietary recall data. [15]. For the recipes of the Korean meals, we referred to "The guidelines of using the Korean Diabetes Food Exchange Table" [16], CAN-Pro 5.0 (Computer Aided Nutritional Analysis Program; The Korean Nutrition Society, Seoul, Korea), and the recipe list book published by the Institute of Traditional Korean Food [17].

The nutritional value of the meals was analyzed using CAN-Pro 5.0. Food elements that were too exotic or regional to be analyzed using CAN-Pro were substituted with the most similar elements in the CAN-Pro database (e.g., raspberries were substituted by cranberries, cannellini beans by horse beans, and fennel or finocchio by onion). Carbohydrate, lipid, and protein rates denote the contributing proportion in total calories but not the proportion of component weight.

\section{Ethical approval and informed consent}

Ethical approval and consent to participate are not applicable as this study did not involve humans or other living organisms. All investigations conformed to the principles outlined in the Declaration of Helsinki. 


\section{ACFS calculation algorithm}

\section{Anti-cancer food scoring system code grade}

(1) ACFS food codes: 22 food elements

( whole grain, red meat, green leafy salad, fish, garlic, soy food, cruciferous vegetable, allium vegetable, cheese, seaweed, fruit, non-starchy vegetable, whitemeat, carotene-rich vegetable, processed meat, selenium-rich food, milk, egg, refined grain, legume, chilli, potato )

(2) Cancer specific grade (CSG) : Each food code is assigned a CSG according to anticancer- or carcinogenic potentials of five cancers (breast, colorectal, stomach, lung, liver).

(3) ACFS code grade: The ACFS code grade is determined by adding the points of the cancer specific grade.

\begin{tabular}{|c|c|c|c|c|c|c|c|c|c|c|c|c|c|}
\hline & & An & cancer food scoring & systen & m code & table & & & & & & & \\
\hline [ CANC & ER SPECIFIC GRADE(CSG) ] & & & - (2) & Cancer st & pecific gra & ade(CSG & & & & & & \\
\hline & Convincing & No & (1) ACFS food code & & & & & & $\begin{array}{l}\text { Summed } \\
\text { code point }\end{array}$ & (3) Code & $\rightarrow[$ Cod & grade poi & it ] \\
\hline & - $\geq 2$ cohort studies or $\geq 5$ case control studies (good qualities) & & & Breast & rectum & Stomach & Lung & Liver & & & & Summed & \\
\hline & & 1 & WG(whole grain) & $c(2)$ & $A(10)$ & $B(5)$ & & & $17(=2+10+5)$ & B & grade & code & point \\
\hline & $\begin{array}{l}\text { - Strong biological plaussibilyty (dose-response) } \\
\text { (-) Substantial unexplained heterogeneity }\end{array}$ & 2 & RM(red meat) & & $A(-10)$ & & $\underline{B}(-5)$ & $\underline{c}(-2)$ & $-17(=-10-5-2)$ & $\mathrm{E}$ & & & \\
\hline & Probable & 3 & GLS(green leafy salad) & c & $B$ & A & B & c & 24 & A & A & $>21$ & 5 \\
\hline (Point 10) & - $\geq 2$ cohort studies or $\geq 5$ case control studies (good qual ities) & 4 & FISH(fish) & c & B & & c & B & 14 & B & & & \\
\hline & - Biological plausibility (dose-response) & 5 & Ga(garlic) & c & A & A & B & & 27 & A & B & $11^{2} 20$ & 4 \\
\hline & - (-) Substantial unexplained heterogeneity & 6 & SF(soy food) & $B$ & c & $\mathrm{B}^{*}$ & & & 12 & B & & & \\
\hline & & 7 & CV(cruciferous vegetable) & c & B & A & B & c & 24 & A & $\mathrm{c}$ & $0^{\sim} 10$ & 3 \\
\hline & & 8 & AV(alium vegetable) & c & A & A & B & c & 29 & A & D & $-10^{2}-1$ & 2 \\
\hline 3 & Limited - suggestive & 9 & $\mathrm{Ch}$ (cheese) & & $\underline{B}$ & & & & 5 & D & & $-10-1$ & 2 \\
\hline (Point 5) & $\begin{array}{l}\text { - } 22 \text { cohort studies or } \geq 5 \text { case control studies (good qualities) } \\
\text { General consistency and biological plausibility }\end{array}$ & 10 & SW(seaweed) & c & c & & & & 4 & c & E & $-20^{2}-11$ & 1 \\
\hline & & 11 & Fr(fruit) & c & B & A & A & B & 32 & A & & & \\
\hline & & 12 & NSV(non-starchy vegetable) & c & $B$ & A & B & c & 24 & A & & & \\
\hline 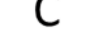 & $\begin{array}{l}\text { Umited - no conciusion } \\
\text { Possibility of relevance }\end{array}$ & 13 & WM(white meat) & & & & & B & 5 & c & & & \\
\hline (Point 2) & $\begin{array}{l}\text { Possibility of relevance } \\
\text { but conclusion cannot be made due to limitation of evidence }\end{array}$ & 14 & CRV(carotene-rich vegetable) & & & c & A & & 12 & B & & & \\
\hline & & 15 & PM(processed meat) & & $\underline{A}$ & $\underline{B}$ & $\underline{B}$ & & -20 & $\mathrm{E}$ & & & \\
\hline
\end{tabular}

\section{Ingredient score calculation}

(1) Divide the meal into constituent ingredients.

(2) Match each ingredient into the relevant ACFS code.

(3) Calculate the food exchange unit with weight of each ingredient

(4) Calculate the food exchange unit ratio.

(FEU of each ingredient / Sum of FEUs in the meal X 100)

(5) Multiply FEU ratios by the code grade points of each ingredient.

(6) Add all (5) value.

[ Examples of ingredient score calculation ]

\begin{tabular}{|c|c|c|c|c|c|c|c|c|c|}
\hline Meal & $\begin{array}{c}\text { (1) } \\
\text { Ingredient }\end{array}$ & $\begin{array}{l}\text { Weight } \\
\text { (g) }\end{array}$ & $\begin{array}{l}\text { (2) } \\
\text { ACFS } \\
\text { code }\end{array}$ & $\begin{array}{l}\text { Code } \\
\text { grade }\end{array}$ & $\begin{array}{l}\text { Code } \\
\text { grade } \\
\text { point }\end{array}$ & $\begin{array}{l}\text { (3) FEU } \\
\text { (Food } \\
\text { Exchange } \\
\text { Unit) }\end{array}$ & $\begin{array}{l}\text { (4) FEU } \\
\text { ratio } \\
(\%)\end{array}$ & $\begin{array}{l}\text { (5) FEU ratio } \\
X \text { code grade } \\
\text { point }\end{array}$ & $\begin{array}{l}\text { (6) } \\
\text { Ingredient } \\
\text { score }\end{array}$ \\
\hline \multirow{8}{*}{$\begin{array}{c}\text { Chinese } \\
\text { style } \\
\text { fried rice }\end{array}$} & White rice & 250 & RG & D & 2 & 3.5 & 53.8 & 107.6 & \\
\hline & Pork & 20 & $\mathrm{RM}$ & $\mathrm{E}$ & 1 & 0.5 & 7.7 & 7.7 & \\
\hline & Egg & 60 & Egg & D & 2 & 1 & 15.4 & 30.8 & \\
\hline & Carrot & 30 & NSV & A & 5 & 0.43 & 6.6 & 33 & \\
\hline & Onion & 40 & AV & A & 5 & 0.57 & 8.8 & 44 & \\
\hline & Pimento & 20 & NSV & A & 5 & 0.29 & 4.5 & 22.5 & 18 \\
\hline & Scallion & 15 & AV & A & 5 & 0.21 & 3.2 & \multirow{2}{*}{$\underset{\text { Sum }}{\downarrow} 16$} & 4 \\
\hline & & & & & \multicolumn{2}{|c|}{ Total FEU : 6.5} & & & 261.6 \\
\hline
\end{tabular}

\section{Cooking modification}

- $H S$ ( high salt) $:>2 g$

- $H F$ (high fat) $:>20 \mathrm{~g}$

$\rightarrow$ Grade is one level lowered

[ Examples of ingredient score calculation - Chinese style fried rice ]

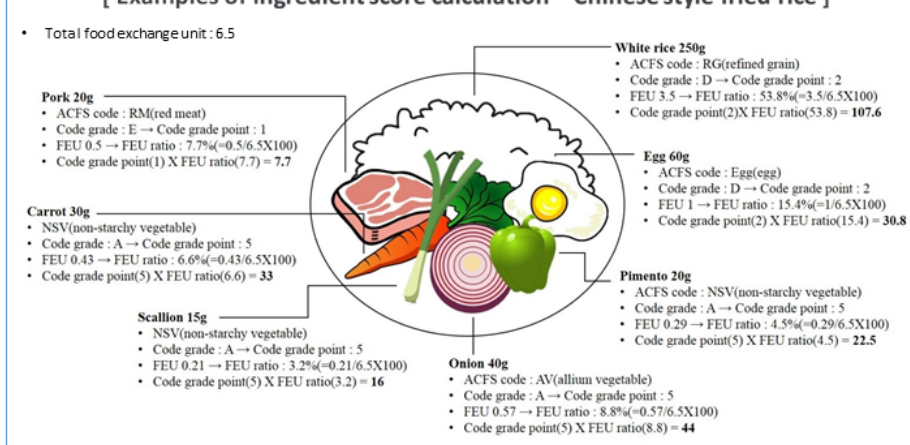

5. ACFS grade interpretation

S Ideal for cancer prevention in terms of composition $\mathrm{S}$ and cooking method.

A Good for cancer prevention in terms of composition

A and cooking method.

B Might have cancer prevention potential

B and some modification can be helpful.

C Difficult to be regarded to have anticancer or carcinogenic

C potential. Modification is recommended.

Might be against cancer prevention.

D Modification is highly recommended.

E Probably against cancer prevention.

Fig. 1. Calculation algorithm of anti-cancer food scoring system (ACFS) 







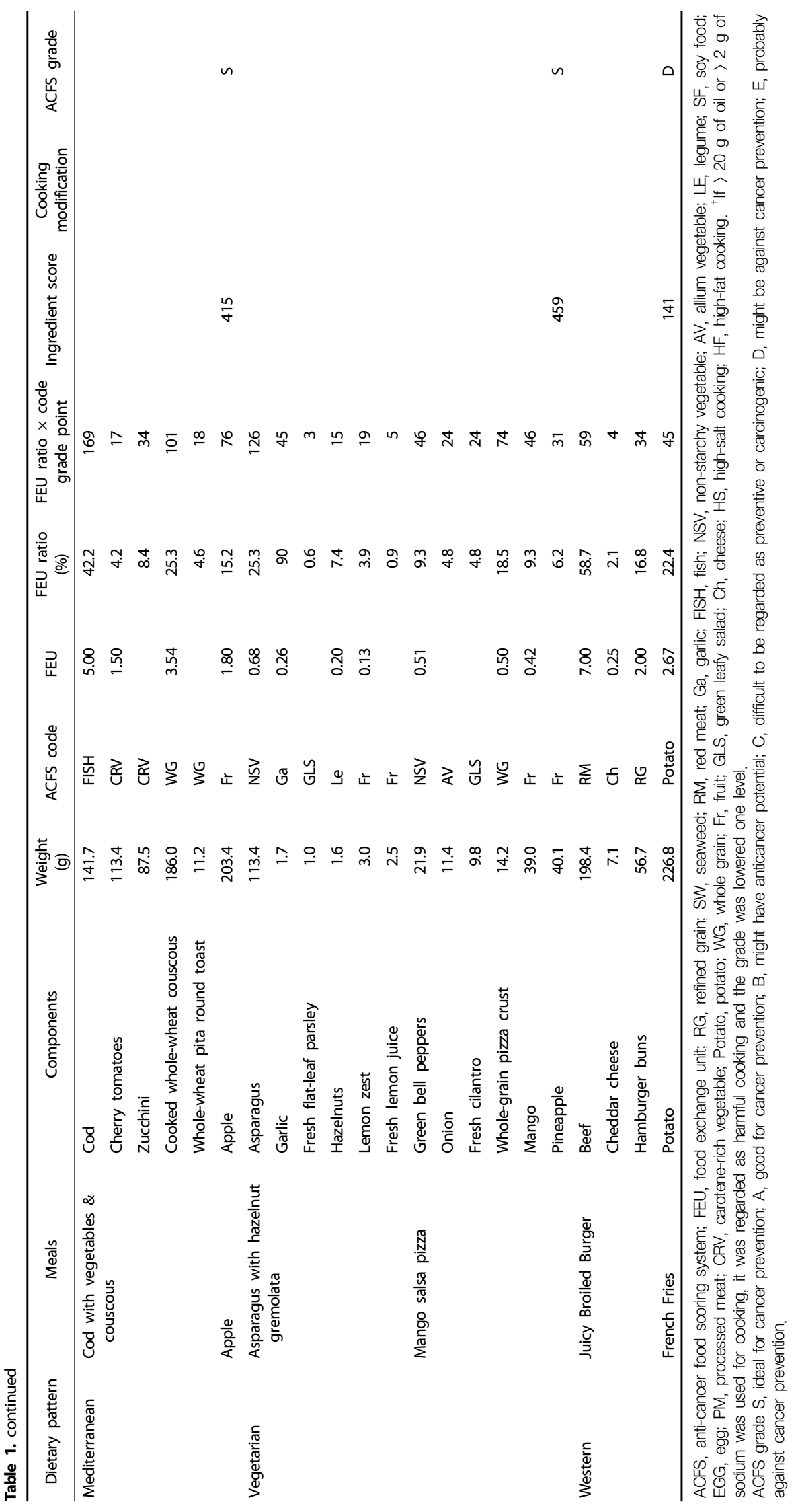




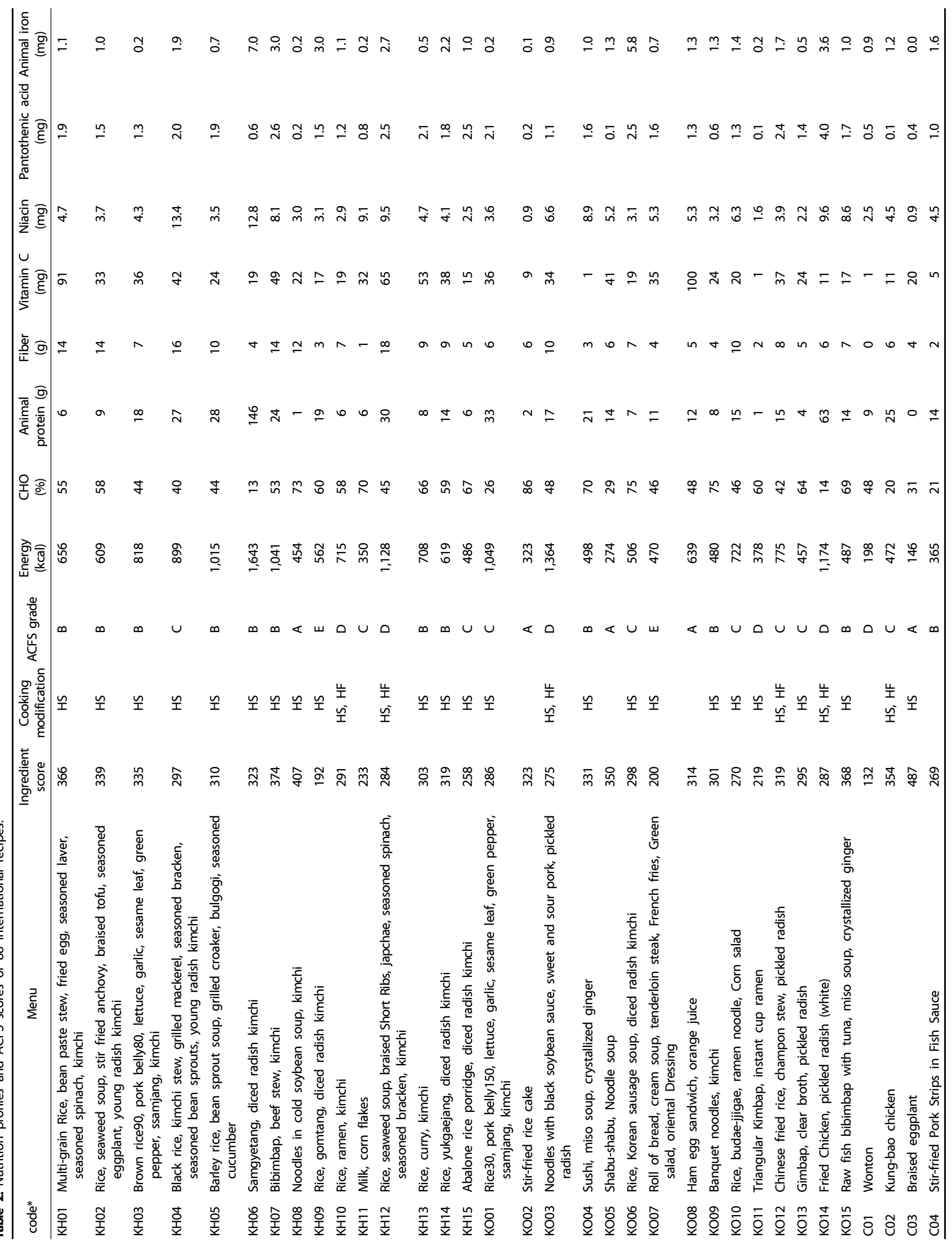




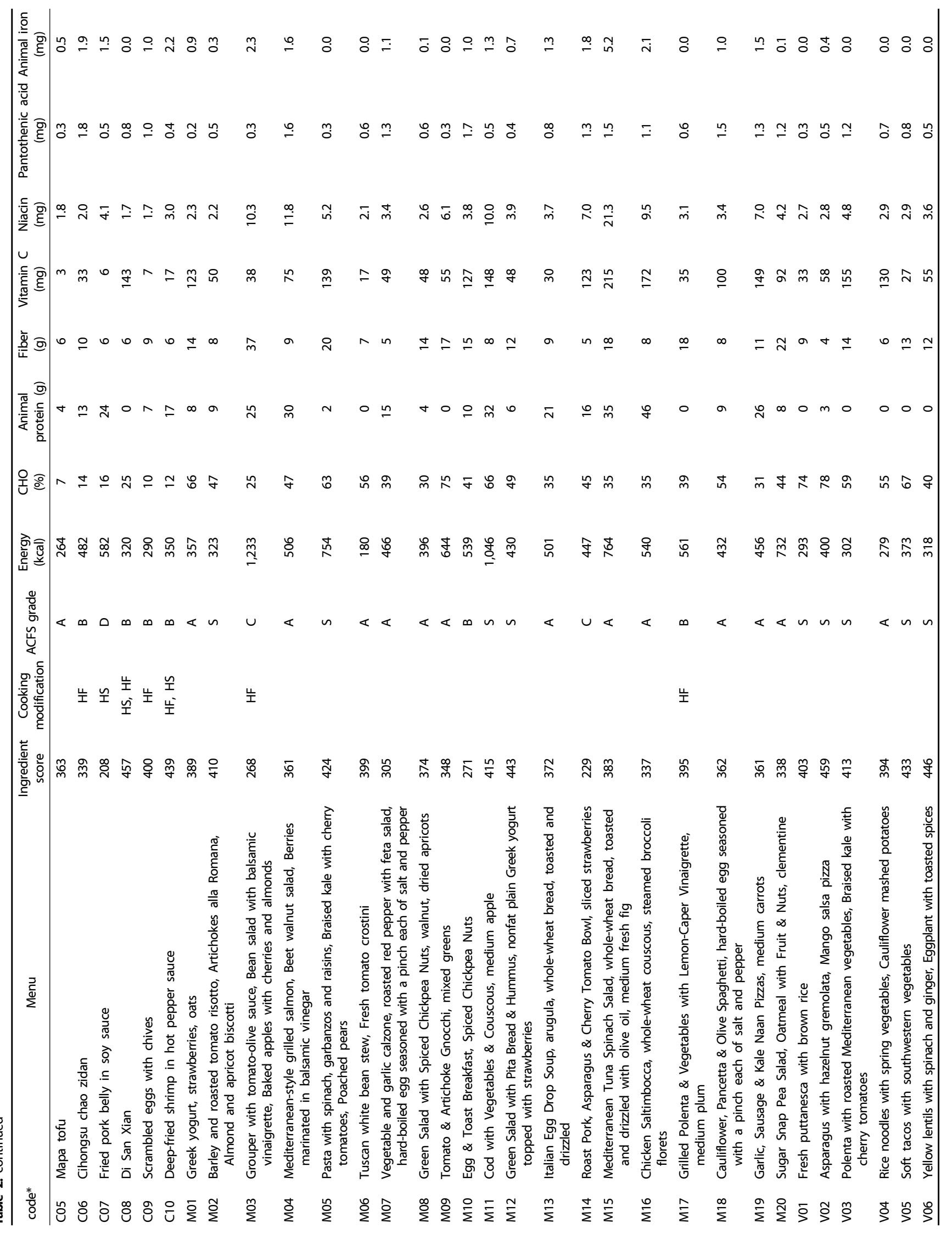


Yeo-Jin Hong et al.

39

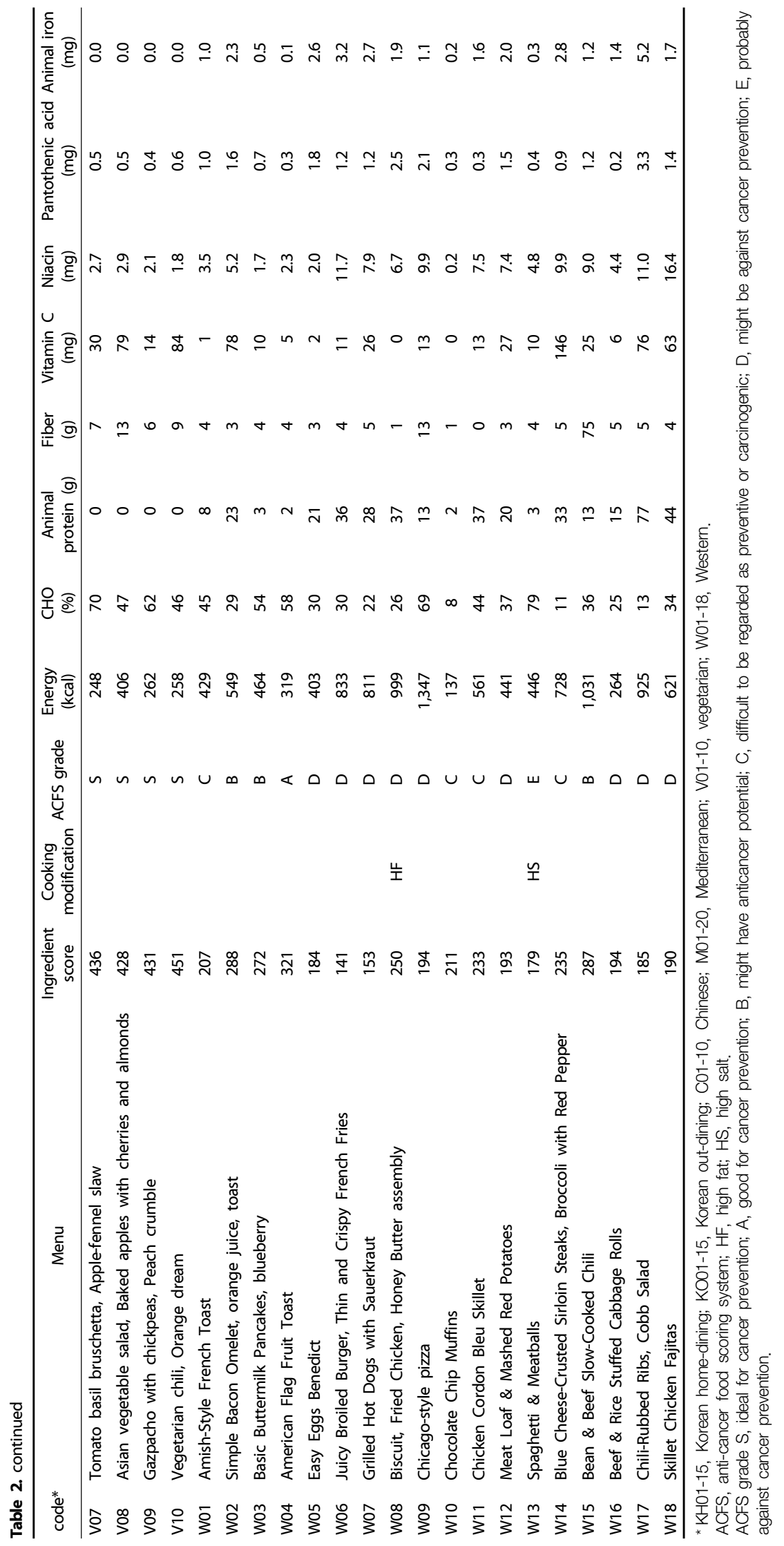


Table 3. Univariate analysis among nutrition profiles and ACFS grade groups.

\begin{tabular}{|c|c|c|c|c|}
\hline & $\begin{array}{c}\text { ACFS E, D } \\
(n=21)\end{array}$ & $\begin{array}{c}\text { ACFS C, B } \\
(n=35)\end{array}$ & $\begin{array}{c}\text { ACFS A, S } \\
(n=34)\end{array}$ & \multirow[t]{2}{*}{$P$-value } \\
\hline & \multicolumn{3}{|c|}{ Median value (range) } & \\
\hline Total calorie (kcal) & $621.0(198.0-1,364.0)$ & $544.0(137.0-1,643.0)$ & $396.0(146.0-1,046.0)$ & $<0.001$ \\
\hline${ }^{*}$ Carbohydrate rate $(\%)$ & $37.0(13.0-76.0)$ & $43.0(8.0-74.0)$ & $51.0(6.0-84.0)$ & 0.012 \\
\hline *Lipid rate (\%) & $39.0(6.0-63.0)$ & $39.5(6.0-85.0)$ & $32.0(3.0-72.0)$ & 0.066 \\
\hline${ }^{*}$ Protein rate $(\%)$ & $19.0(10.0-35.0)$ & $16.0(6.0-37.0)$ & $18.0(5.0-46.0)$ & 0.762 \\
\hline Carbohydrate (g) & $55.0(16.0-227.0)$ & $69.5(3.0-135.0)$ & $49.0(4.0-173.0)$ & 0.316 \\
\hline Total fat (g) & $25.0(3.0-77.0)$ & $25.0(3.0-86.0)$ & $13.0(1.0-35.0)$ & $<0.001$ \\
\hline Plant fat (g) & $8.0(0-42.0)$ & $11.5(0-48.0)$ & $9.0(1-25.0)$ & 0.563 \\
\hline Animal fat (g) & $18.0(0-53.0)$ & $9.0(0-84.0)$ & $1.0(0-13.0)$ & $<0.001$ \\
\hline Protein (g) & $28.0(10.0-81.0)$ & $24.5(3.0-151.0)$ & $17.0(2.0-61.0)$ & 0.004 \\
\hline Protein, plant (g) & $7.0(3.0-30.0)$ & $8.0(1.0-64.0)$ & $12.0(2.0-31.0)$ & 0.059 \\
\hline Animal protein (g) & $20.0(1.0-77.0)$ & $14.0(0-146.0)$ & $3.0(0-46.0)$ & $<0.001$ \\
\hline Fiber (g) & $4.0(0-18.0)$ & $6.5(0-75.0)$ & $9.0(4.0-22.0)$ & $<0.001$ \\
\hline Fiber, water soluble (g) & $0.40(0-4.30)$ & $0.85(0-10.30)$ & $1.30(0.2-3.10)$ & 0.001 \\
\hline Fiber, non-soluble (g) & $2.40(0-11.80)$ & $3.90(0-61.30)$ & $4.30(1.20-11.0)$ & 0.055 \\
\hline Water (g) & $188.0(43.0-536.0)$ & $240.5(21.0-494.0)$ & $274.0(118.0-620.0)$ & 0.076 \\
\hline Vitamin A (RAE) & $104.0(4.0-386.0)$ & $156.0(12.0-518.0)$ & $135.0(7.0-931.0)$ & .0 .261 \\
\hline Retinol $(\mu \mathrm{g})$ & $22.0(0-235.0)$ & $23.5(0-371.0)$ & $32.0(0-173.0)$ & 0.275 \\
\hline Beta carotene $(\mu \mathrm{g})$ & $477.0(1.0-4,138.0)$ & $1235.0(4.0-5,058.0)$ & $1352.0(40.0-10,680.0)$ & 0.055 \\
\hline Vitamin $D(\mu \mathrm{g})$ & $0.37(0-5.13)$ & $0.36(0-20.00)$ & $\sim 0.0(0-45.34)$ & 0.037 \\
\hline Vitamin E (mg) & $3.00(1.00-47.0)$ & $7.50(1.00-36.0)$ & $4.00(1.00-13.0)$ & 0.270 \\
\hline Vitamin K ( $\mu \mathrm{g})$ & $12.0(0-364.0)$ & $60.5(0-612.0)$ & $68.0(6.00-1093.0)$ & 0.014 \\
\hline Vitamin C (mg) & $13.0(0-76.0)$ & $28.5(0-146.0)$ & $55.0(3.0-215.0)$ & $<0.001$ \\
\hline Thiamine (mg) & $0.56(0.20-2.01)$ & $0.58(0.04-1.92)$ & $0.57(0.12-1.78)$ & 0.957 \\
\hline Riboflavin (mg) & $0.50(0.10-1.60)$ & $0.45(0.10-1.60)$ & $0.40(0.10-1.10)$ & 0.041 \\
\hline Niacin (mg) & $6.60(1.60-16.40)$ & $4.20(0.20-13.40)$ & $3.00(0.90-21.30)$ & 0.009 \\
\hline Vitamin $B_{6}(\mathrm{mg})$ & $0.50(0.10-1.80)$ & $0.50(0.0-1.60)$ & $0.40(0.20-1.50)$ & 0.131 \\
\hline Folic acid $(\mu \mathrm{g})$ & $106.0(14.0-418.0)$ & $176.5(15.0-806.0)$ & $153.0(35.0-698.0)$ & 0.123 \\
\hline Vitamin $B_{12}(\mu \mathrm{g})$ & $0.80(0.10-5.00)$ & $0.95(0-13.2)$ & $0.20(0-8.40)$ & 0.002 \\
\hline Pantothenic acid (mg) & $1.40(0.10-4.00)$ & $1.30(0.10-2.60)$ & $0.50(0.10-1.60)$ & $<0.001$ \\
\hline Biotin $(\mu \mathrm{g})$ & $\sim 0.0(0-3.50)$ & $\sim 0.0(0-4.08)$ & $\sim 0.0(0-9.00)$ & 0.249 \\
\hline Calcium (mg) & $89.0(22.0-289.0)$ & $118.0(27.0-427.0)$ & $130.0(28.0-723.0)$ & 0.035 \\
\hline Calcium, plant (mg) & $35.0(14.0-243.0)$ & $86.5(2.0-415.0)$ & $93.0(28.0-546.0)$ & $<0.001$ \\
\hline Calcium, meat (mg) & $33.0(0-259.0)$ & $30.0(0-210.0)$ & $13.0(0-271.0)$ & 0.107 \\
\hline Phosphorous (mg) & $406.0(106.0-1,147.0)$ & $362.0(51.0-1,216.0)$ & $353.0(51.0-921.0)$ & 0.356 \\
\hline Sodium (mg) & $1104.0(167.0-3,048.0)$ & $1021.5(117.0-3,557.0)$ & $351.0(13.0-3,442.0)$ & $<0.001$ \\
\hline Chloride (mg) & $16.1(0-1,712.0)$ & $13.8(0-253.8)$ & $3.1(0-317.2)$ & 0.124 \\
\hline Potassium (mg) & $782.0(175.0-2,047.0)$ & $767.0(58.0-3,779.0)$ & $793.0(232.0-1,982.0)$ & 0.425 \\
\hline Magnesium (mg) & $33.0(3.00-160.0)$ & $34.0(2.00-270.0)$ & $40.0(6.00-141.0)$ & 0.219 \\
\hline Iron (mg) & $3.70(1.40-10.40)$ & $4.55(0.30-18.30)$ & $4.60(0.70-15.60)$ & 0.862 \\
\hline Plant iron (mg) & $2.40(0.50-7.70)$ & $3.45(0.10-17.00)$ & $3.50(0.70-10.50)$ & 0.059 \\
\hline Animal iron (mg) & $1.70(0.20-5.20)$ & $1.15(0-7.00)$ & $0.10(0-5.20)$ & $<0.001$ \\
\hline Zinc (mg) & $3.8(0.80-12.6)$ & $3.3(0.30-12.6)$ & $2.0(0.40-6.3)$ & 0.006 \\
\hline Copper ( $\mu \mathrm{g})$ & $198.0(25.0-486.0)$ & $211.0(20.0-1,340.0)$ & $169.0(19.0-479.0)$ & 0.303 \\
\hline Fluorine (mg) & $\sim 0.0(0-0.05)$ & $\sim 0.0(0-0.05)$ & $\sim 0.0(0-0.08)$ & 0.964 \\
\hline Manganese (mg) & $0.38(0.07-1.06)$ & $0.62(0.01-4.92)$ & $0.49(0.07-1.84)$ & 0.656 \\
\hline lodine $(\mu \mathrm{g})$ & $4.90(0-590.5)$ & $6.30(0-580.0)$ & $2.30(0-50.40)$ & 0.131 \\
\hline Selenium ( $\mu \mathrm{g})$ & $29.6(0.10-137.2)$ & $20.6(1.00-71.6)$ & $13.6(0.60-121.9)$ & 0.018 \\
\hline Cobalt $(\mu \mathrm{g})$ & $\sim 0.0$ & $\sim 0.0(0-56.3)$ & $\sim 0.0(0-0.07)$ & 0.961 \\
\hline Molybdenum ( $\mu \mathrm{g}$ ) & $\sim 0.0(0-4.08)$ & $0.10(0-12.6)$ & $0.15(0-2.79)$ & 0.125 \\
\hline Cholesterol (mg) & $130.0(7.00-495.0)$ & $84.0(0-493.0)$ & $17.0(0-268.0)$ & $<0.001$ \\
\hline
\end{tabular}

* Rates of proportions contributing total calories of meals.

ACFS, Anti-cancer food scoring system; RAE, Retinol Activity Equivalent

ACFS grade S, ideal for cancer prevention; A, good for cancer prevention; B, might have anticancer potential; C, difficult to be regarded as preventive or carcinogenic;

$\mathrm{D}$, might be against cancer prevention; E, probably against cancer prevention. 


\section{Statistical analyses}

Univariate analyses were performed using the JonckheereTerpstra test to identify trends among ACFS grade subgroups. The variables with $P$ values of $<0.05$ in the Jonckheere-Terpstra test were included in the multivariate analyses. Among the variables, possibly duplicated variables (e.g., total fat and animal fat, total fiber and water-soluble fiber, calcium and plant calcium) were filtered to be included in the multivariate analysis using the following criteria prioritized in numerical order: 1) the variable with higher statistical significance; 2) the specific variable rather than the general one. Simple nutritional or proportional values including total calories and carbohydrate, lipid, and protein rates contributing to the total calories of meals were not included in the multivariate analysis. Multivariate analyses were performed via multiple regression analyses, using the backward elimination method. The probabilities of removal and entry were 0.10 and 0.05 , respectively. Standardized $\beta$ coefficients and non-standardized $\beta$ coefficients were presented to identify the comparative significance of each variable. All statistical tests were performed using SPSS version 23.0 (IBM Corp., Armonk, NY, USA).

\section{RESULTS}

\section{Nutrition profiles and ACFS scores}

A total of 88 international recipes, including 15 Korean homedining, 15 Korean out-dining, 10 Chinese, 20 Mediterranean, 10 vegetarian, and 18 Western recipes, were included in this study and analyzed. The number of recipes in the highest anticarcinogenic category (S grade) was 13 (14.8\%), followed by 20 in A grade (22.7\%), 21 in B grade (23.9\%), 15 in C grade (17.0\%), 16 in D grade (18.2\%), and 3 in $E$ grade (3.4\%). All $13 \mathrm{~S}$ grade recipes belonged to vegetarian or Mediterranean recipes. The median ACFS grades, derived from ingredient scores after considering the harmful cooking methods, were $B$, $C, B, A, S$, and D for Korean home-dining, Korean out-dining, Chinese, Mediterranean, vegetarian, and Western recipes, respectively.

For all the 88 recipes, the ingredient scores ranged from 132 to 487 with a median value of 320 and the energy values ranged from 137 to $1,643 \mathrm{kcal}$ with a median value of $484 \mathrm{kcal}$. The median ingredient scores of Korean home-dining, Korean outdining, Chinese, Mediterranean, vegetarian, and Western recipes were 310 (range: 192-407), 298 (200-368), 359 (132-487), 367 (229-443), 432 (394-459), and 201 (141-321), respectively; median energy values in kcal were 708 (350-1643), 498 (274-1364), 335 (146-582), 504 (180-1233), 298 (248-406), and 555 (137-1347), respectively.

The names of the recipes, ingredient scores, ACFS grades, calories, and brief nutritional profiles are presented in Table 2. The full nutritional profile is described in Supplementary file S1.

\section{Nutritional analyses}

For univariate analysis, we categorized the 6 ACFS grades into 3 groups: $S$ and $A ; B$ and $C ; D$ and $E$. In the analysis, the following factors were correlated with the ACFS grade groups $(P<0.05)$ : total calories, total fat, animal fat, animal protein, total protein, vitamin $D$, riboflavin, niacin, vitamin $B_{12}$, pantothenic acid,
Table 4. Result of the multivariate analysis on statistically significant factors obtained from the univariate analysis.

\begin{tabular}{lcccc}
\hline & non-standardized & \multicolumn{3}{c}{ standardized } \\
\cline { 2 - 5 } & $\beta$ & SE & $\beta$ & $P$ \\
\hline Significant factors & & & & \\
Animal fat & -0.030 & 0.013 & -0.330 & 0.020 \\
Animal iron & -0.364 & 0.155 & -0.345 & 0.021 \\
Niacin & -0.138 & 0.047 & -0.359 & 0.004 \\
Fiber & 0.029 & 0.013 & 0.183 & 0.034 \\
Animal protein & 0.037 & 0.013 & 0.525 & 0.006 \\
Vitamin C & 0.013 & 0.003 & 0.420 & $<0.001$ \\
Non-significant trends & & & & \\
Pantothenic acid & -0.349 & 0.184 & -0.192 & 0.062 \\
Sodium & 0 & 0 & -0.175 & 0.077 \\
Vitamin B & 0.123 & 0.068 & 0.193 & 0.074 \\
\hline
\end{tabular}

SE: standard error

sodium, animal iron, zinc, selenium, and cholesterol (negative trends); carbohydrate rate, fiber, water-soluble fiber, vitamin $\mathrm{K}$, vitamin $C$, and plant calcium (positive trends). The results of the univariate analysis are summarized in Table 3. Multivariate analysis was performed on factors found to be significant in the univariate analysis. The following variables were included: animal fat, animal protein, vitamin $D$, riboflavin, niacin, vitamin $B_{12}$, pantothenic acid, sodium, animal iron, zinc, selenium, cholesterol, fiber, vitamin $\mathrm{K}$, vitamin $\mathrm{C}$, and plant calcium. For multivariate analysis, the 6 ACFS grades and the quantitative amounts of nutrition profiles were used. Six profiles were found to be statistically significant: animal fat (standardized $\beta=-0.330$, $P=0.020$ ), animal iron (standardized $\beta=-0.345, P=0.021$ ), and niacin (standardized $\beta=-0.359, P=0.004$ ) (negative trends); fiber (standardized $\beta=0.183, P=0.034$ ), animal protein (standardized $\beta=0.525, P=0.006$ ), and vitamin $C$ (standardized $\beta=0.420$, $P<0.001$ ) (positive trends). Two profiles showed non-significant negative trends $(P<0.1)$ : pantothenic acid (standardized $\beta=$ -0.192, $P=0.062$ ) and sodium (standardized $\beta=-0.175, P=$ 0.077). Vitamin $B_{12}$ showed a non-significant positive trend (standardized $\beta=0.193, P=0.074$ ). Each standardized $\beta$ value represented the relative significance of each variable. These results are summarized in Table 4.

\section{DISCUSSION}

The present study demonstrated that the ACFS calculation model was significantly associated with known healthy and unhealthy nutritional factors. Univariate analysis showed that the ACFS model was strongly negatively correlated with factors such as animal fat $(P<0.001)$, sodium $(P<0.001)$, and cholesterol $(P<0.001)$, which are generally considered to be harmful to health, and strongly positively correlated with factors such as fiber $(P<0.001)$, vitamin $C(P<0.001)$, and plant calcium $(P<0.002)$, which are considered beneficial.

Multivariate analysis showed that the ACFS model is negatively correlated with animal fat, animal iron, and niacin and positively correlated with fiber, vitamin $C$, and animal protein $(P s<0.05)$. Pantothenic acid and sodium had non-significant negative trends, while vitamin $\mathrm{B}_{12}$ showed a positive trend $(P \mathrm{~s}<0.1)$. 
In the recently updated WCRF and AICR third expert report, red meat consumption showed strong evidence of increased risk of colorectal cancer and limited evidence of increased risks of nasopharyngeal, lung, and pancreatic cancers [18]. The most well-known causes of cancer related to red meat consumption are heterocyclic amines and polycyclic aromatic hydrocarbons, which are carcinogens that are produced on high-temperature cooking [19]. Besides, saturated fat itself has been known to be related to the risk of cancers, including breast, lung, and colorectal cancers [20-22]. This evidence aligns with our study results concerning animal fat. The iron components in animal products were found to be associated with the ACFS grade in our study. Heme iron, which is abundant in red meat, was known to be related to tumorigenesis by stimulating the endogenous formation of $\mathrm{N}$-nitroso compounds [19]. Body iron stores, which were assessed by serum iron and transferrin saturation of total iron-binding capacity, were reported to increase the incidence of cancer in large population studies $[23,24]$, although these results need to be verified by studies with more nutritional perspectives.

Animal protein was found to have a positive relationship with the ACFS grade in multivariate analysis, which reflects its anticarcinogenic potential. Interestingly, animal protein showed a negative trend in the univariate analysis but reversed to have a positive trend in the multivariate analysis. We hypothesized that animal protein from poultry and fish might affect these results and the carcinogenic effect of meat might be more related to other components such as fat or iron, although further studies are warranted. Poultry intake was reported to be inversely associated with colorectal cancer risk in a recent meta-analysis, with a risk ratio (RR) of 0.89 (95\% confidence interval [Cl], 0.81-0.97) for a $50 \mathrm{~g} /$ day increase uptake of poultry [25]. A meta-analysis study reported an inverse relationship between poultry intake and lung cancer (RR 0.91, 95\% Cl: 0.85-0.97) [26], and a population-based case control study showed a similar relationship between pancreatic cancer and poultry intake (odds ratio: $0.7,95 \% \mathrm{Cl}$ : 0.5-1.0) [27]. Fish intake was reported to have limited-suggestive evidence of decreasing the risk of liver and colorectal cancers in the third expert report of the WCRF and the AICR [18]. In a meta-analysis, the pooled RR of the highest fish intake category compared to the lowest fish intake category was 0.88 ( $95 \% \mathrm{Cl}: 0.78-1.00)$ for colorectal cancer incidence [28]. For liver cancer, the pooled RR for the highest fish intake quartile was 0.82 (95\% Cl: 0.71-0.94), as per a recent meta-analysis study [29]. Unfortunately, we cannot fully explain the results of the meta-analyses with regard to the mechanisms, as the mechanisms are not fully understood yet and are masked by confounding factors $[25,30]$. We hope that future studies investigating the cancer protective mechanisms of poultry and fish can explain these results and show a correlation with ACFS.

Foods containing dietary fiber had strong protective evidence for colorectal cancer in the third expert report of the WCRF and the AICR [31]. In humans, fibers can be fermented and metabolized by the colonic microflora, forming short-chain fatty acids, such as butyrate, which have an anti-proliferative effect on colon cancer. Additionally, fibers can reduce the transit time of fecal bulk and lessen the interaction between fecal mutagens and colonic mucosa [32,33]. Dietary fiber was also associated with decreased risk of breast cancer in a meta-analysis, with an RR of 0.95 per $10 \mathrm{~g} /$ day intake [34]. The European Prospective Investigation into Cancer and Nutrition study, which included a prospective cohort of $>500,000$, reported that colorectal, breast, and liver cancers were inversely associated with dietary fiber intake [35]. Vitamin $C$ has been known to prevent cancer and proven to have a protective effect on esophageal, laryngeal, oral cavity, pancreatic, stomach, rectal, breast, and cervical cancers, which are strongly consistent with the results of the previous meta-analyses [36,37]. It was also reported to have limited -suggestive evidence of decreasing the risks of colorectal and lung cancers in the third expert report of the WCRF and the AICR [31].

The relationship between niacin intake and cancer risk is largely unexplored. Although there is some in vivo evidence that niacin status influences carcinogenesis in a tissue-specific manner, evidence from human studies is lacking [38]. In a recent clinical study, niacin intake was inversely associated with squamous cell carcinoma of the skin but showed a positive relationship with basal cell carcinoma of the skin [39]. Since ACFS is based on meal recipes (not nutritional components), correlation with niacin, which is abundant both in plant foods (e.g., peas and barley have high ACFS score) and red meats (low ACFS scores), might not be robust. Future clinical studies evaluating the anti-cancer or carcinogenic effects of niacin are necessary.

Among the factors with non-significant trends, vitamin $B_{12}$ was shown to have an inverse relationship with cancer risk in recent studies. A dose-response relationship between dietary intake of vitamin $B_{12}$ and decreased risk of colorectal cancer was shown in a recent meta-analysis (pooled RR: 091, 95\% Cl: $0.86-0.98$ ) [40]. A recent case-control study revealed that low vitamin $B_{12}$ concentration was associated with a 5.8-fold higher risk of non-cardia gastric cancer [41]. Another study also found a significant association between low levels of plasma vitamin $\mathrm{B}_{12}$ and hepatocellular carcinoma risk (odds ratio: $2.01,95 \% \mathrm{Cl}$ : 1.02-3.98) [42]. Sodium was also negatively associated with the ACFS grade with non-significant trends. The positive association between sodium and cancer is most well-known for gastric cancer [43], and the third expert report by the WCRF and the AICR also reported strong evidence between Cantonese-style salted fish and nasopharyngeal cancer [44]. Although relevant effects of pantothenic acid have not been extensively studied in the literature, Hutschenreuther et al. [45] reported that the aggressiveness of tumor cells might be related to pantothenic acid in a cell-line study. This component should be investigated in future to explain our results.

It has long been necessary to categorize and quantify factors that can prevent or increase the risk of cancer. The International Agency for Research on Cancer systematically classifies substances that may or may not be carcinogenic [46]. The expert reports of the WCRF and the AICR, probably the most comprehensive review regarding cancer prevention, diet, and lifestyle, have proved their clinical efficacy in recent prospective trials [7]. Our ACFS model systematically analyzed the literature regarding diet and cancer prevention, based on the classification system from the WCRF and AICR [47], and enabled quantitative anti- 
cancer scoring of a wide-range of everyday meals. Consequently, our model allows everyone without medical or nutritional expertise to obtain an evidence-based anti-cancer or carcinogenic score of their meals.

Although several models have already been published to assess the health index of food, our model is unique because of the following reasons. Scoring methods such as aggregate nutrient density index (ANDI) [48] and $\mathrm{NuVal}^{\circledR}$ [49], which are developed in the US and commonly used, are composed of assessments focusing on overall health, while the ACFS focuses on cancer prevention or carcinogenicity. Additionally, the ACFS evaluates complete meals actually consumed in daily life, while the ANDI and NuVal evaluate food components. Healthy Eating Index (HEl) [50] and Dietary Quality Index (DQI) [51] are tools for evaluating meals rather than individual food components. However, these tools do not focus on cancer but on overall health or known nutritional expertise. Hence, the ACFS model is unique in evaluating daily meals, yielding indexes focused on cancer prevention and carcinogenicity.

The purpose of the present study was to provide a nutritional basis for the efficacy of the ACFS calculation model. Although ACFS was based on a comprehensive systematic review, there is a lack of substantive evidence to demonstrate its efficacy. This study could facilitate the design of research demonstrating the clinical utility of ACFS. Although we included 88 recipes from 6 international categories, probably the number of samples should be further increased. Representing each diet category with 10-20 recipes also has limitations. We performed fairly objective selections of representative foods for Asian recipes, but we were forced to rely mainly on the author's discussion in the corresponding websites for the selection of Western meals. Along with the clinical study design, to enhancement of nutritional reliability using larger validation with more number of international recipes will be the subject of our future studies.

We have shown that the ACFS grade generally corresponds with commonly known anti-cancer or carcinogenic factors. Although the effect of some factors needs to be elucidated through additional studies, the ACFS grade has been well correlated with factors such as fiber, vitamin $C$, vitamin $B_{12}$, sodium, animal fat, and iron. Hence, our calculation model could be named ACFS 2.0, reflecting the newly drawn reliability of this study. Future clinical studies along with wider validation are warranted to firmly prove the utility of the model.

\section{CONFLICT OF INTEREST}

The author declares no potential conflicts of interests.

\section{ORCID}

Yeo-Jin Hong: https://orcid.org/0000-0002-1937-3849

Jeongseon Kim: https://orcid.org/0000-0002-0889-2686

Hye Yoon Lee: https://orcid.org/0000-0001-9077-1412

Chai Hong Rim: https://orcid.org/0000-0001-7431-4588

\section{REFERENCES}

1. GBD 2015 Mortality and Causes of Death Collaborators. Global, regional, and national life expectancy, all-cause mortality, and cause-specific mortality for 249 causes of death, 1980-2015: a systematic analysis for the global burden of disease study 2015. Lancet 2016;388:1459-544.

2. National Cancer Information Center. Title [Internet]. Goyang: National Cancer Information Center; year [cited 2019 February 1]. Available from: https://www.cancer.go.kr/lay1/S1T645C646/contents.do.

3. National Center for Health Statistics. Health, United States, 2016: With Chartbook on Long-Term Trends in Health. Hyattsville (MD): National Center for Health Statistics; 2017.

4. Nagao $\mathrm{M}$, Tsugane $\mathrm{S}$. Cancer in Japan: prevalence, prevention and the role of heterocyclic amines in human carcinogenesis. Genes Environ 2016;38:16.

5. Anand $P$, Kunnumakkara $A B$, Sundaram $C$, Harikumar $K B$, Tharakan ST, Lai OS, Sung B, Aggarwal BB. Cancer is a preventable disease that requires major lifestyle changes. Pharm Res 2008;25:2097-116.

6. Doll R, Peto R. The causes of cancer: quantitative estimates of avoidable risks of cancer in the United States today. J Natl Cancer Inst 1981;66:1191-308.

7. Hastert TA, Beresford SA, Sheppard L, White E. Adherence to the WCRF/AICR cancer prevention recommendations and cancer-specific mortality: results from the vitamins and lifestyle (VITAL) study. Cancer Causes Control 2014;25:541-52.

8. McCann SE, Marshall JR, Brasure JR, Graham S, Freudenheim JL. Analysis of patterns of food intake in nutritional epidemiology: food classification in principal components analysis and the subsequent impact on estimates for endometrial cancer. Public Health Nutr 2001;4:989-97.

9. Kerr J, Anderson C, Lippman SM. Physical activity, sedentary behaviour, diet, and cancer: an update and emerging new evidence. Lancet Oncol 2017;18:e457-71.

10. Schulze MB, Hoffmann K, Kroke A, Boeing $H$. Dietary patterns and their association with food and nutrient intake in the European prospective investigation into cancer and nutrition (EPIC)-Potsdam study. Br J Nutr 2001;85:363-73.

11. Navarro Silvera SA, Mayne ST, Risch $H$, Gammon MD, Vaughan TL, Chow WH, Dubrow R, Schoenberg JB, Stanford JL, West AB, Rotterdam H, Blot WJ, Fraumeni JF Jr. Food group intake and risk of subtypes of esophageal and gastric cancer. Int J Cancer 2008;123:852-60.

12. $\operatorname{Rim} \mathrm{CH}$. Development of quantitative index evaluating anticancer or carcinogenic potential of diet: the anti-cancer food scoring system 1.0. Nutr Res Pract 2018;12:52-60.

13. World Cancer Research Fund/American Institute for Cancer Research. Food, Nutrition, Physical Activity, and the Prevention of Cancer: a Global Perspective. Washington, D.C.: American Institute for Cancer Research; 2007.

14. Hensrud D, Nelson J, Forberg C, Callahan M, Giblin S. The New Mayo Clinic Cookbook: Eating Well for Better Health. Menlo Park (CA): Oxmoor House; 2012.

15. Kweon S, Kim Y, Jang MJ, Kim Y, Kim K, Choi S, Chun C, Khang $\mathrm{YH}$, Oh K. Data resource profile: the Korea national health and nutrition examination survey (KNHANES). Int J Epidemiol 2014;43: 69-77.

16. Korean Diabetes Association. Korean food exchange list [Internet]. Seoul: Korean Diabetes Association; 2010 [cited 2018 August 10]. Available from: http://www.diabetes.or.kr/english/resource/index. php?category=3. 
17. Institute of Traditional Korean Food. Beautiful Korean Recipes 300 Selections. Seoul: Hallym Publishing; 2008.

18. World Cancer Research Fund International. Meat, Fish, and Dairy Products and the Risk of Cancer. London: World Cancer Research Fund International; 2018.

19. Cross AJ, Sinha R. Meat-related mutagens/carcinogens in the etiology of colorectal cancer. Environ Mol Mutagen 2004;44:44-55.

20. Alavanja MC, Brown CC, Swanson C, Brownson RC. Saturated fat intake and lung cancer risk among nonsmoking women in Missouri. J Natl Cancer Inst 1993;85:1906-16.

21. Sieri $S$, Krogh $V$, Ferrari $P$, Berrino $F$, Pala V, Thiébaut AC, Tjønneland A, Olsen A, Overvad K, Jakobsen MU, Clavel-Chapelon F, Chajes $V$, Boutron-Ruault MC, Kaaks R, Linseisen J, Boeing $H$, Nöthlings $U$, Trichopoulou A, Naska A, Lagiou P, Panico S, Palli D, Vineis $P$, Tumino R, Lund E, Kumle M, Skeie G, González CA, Ardanaz E, Amiano P, Tormo MJ, Martínez-García C, Quirós JR, Berglund G, Gullberg B, Hallmans $G$, Lenner $P$, Bueno-de-Mesquita HB, van Duijnhoven FJ, Peeters PH, van Gils CH, Key TJ, Crowe FL, Bingham S, Khaw KT, Rinaldi S, Slimani N, Jenab M, Norat T, Riboli E. Dietary fat and breast cancer risk in the European prospective investigation into cancer and nutrition. Am J Clin Nutr 2008;88:1304-12.

22. Reddy BS. Types and amount of dietary fat and colon cancer risk: Prevention by omega-3 fatty acid-rich diets. Environ Health Prev Med 2002;7:95-102.

23. van Asperen IA, Feskens EJ, Bowles $\mathrm{CH}$, Kromhout D. Body iron stores and mortality due to cancer and ischaemic heart disease: a 17-year follow-up study of elderly men and women. Int J Epidemiol 1995;24:665-70.

24. Knekt $P$, Reunanen $A$, Takkunen $H$, Aromaa $A$, Heliövaara $M$, Hakulinen T. Body iron stores and risk of cancer. Int J Cancer 1994;56:379-82.

25. Shi Y, Yu PW, Zeng DZ. Dose-response meta-analysis of poultry intake and colorectal cancer incidence and mortality. Eur J Nutr 2015;54:243-50

26. Yang WS, Wong MY, Vogtmann E, Tang RQ, Xie L, Yang YS, Wu QJ, Zhang W, Xiang YB. Meat consumption and risk of lung cancer: evidence from observational studies. Ann Oncol 2012;23:3163-70.

27. Chan JM, Wang F, Holly EA. Pancreatic cancer, animal protein and dietary fat in a population-based study, San Francisco Bay Area, California. Cancer Causes Control 2007;18:1153-67.

28. Geelen A, Schouten JM, Kamphuis C, Stam BE, Burema J, Renkema $J M$, Bakker EJ, van't Veer $P$, Kampman E. Fish consumption, n-3 fatty acids, and colorectal cancer: a meta-analysis of prospective cohort studies. Am J Epidemiol 2007;166:1116-25.

29. Huang RX, Duan YY, Hu JA. Fish intake and risk of liver cancer: a meta-analysis. PLoS One 2015;10:e0096102.

30. Huang XE, Hirose K, Wakai K, Matsuo K, Ito H, Xiang J, Takezaki $\mathrm{T}$, Tajima K. Comparison of lifestyle risk factors by family history for gastric, breast, lung and colorectal cancer. Asian Pac J Cancer Prev 2004;5:419-27.

31. World Cancer Research Fund International. Wholegrains, Vegetables and Fruit and the Risk of Cancer. London: World Cancer Research Fund International; 2018.

32. Slavin JL. Mechanisms for the impact of whole grain foods on cancer risk. J Am Coll Nutr 2000;19:300S-307S.

33. Bingham SA. Mechanisms and experimental and epidemiological evidence relating dietary fibre (non-starch polysaccharides) and starch to protection against large bowel cancer. Proc Nutr Soc
1990;49:153-71.

34. Aune D, Chan DS, Greenwood DC, Vieira AR, Rosenblatt DA, Vieira $\mathrm{R}$, Norat T. Dietary fiber and breast cancer risk: a systematic review and meta-analysis of prospective studies. Ann Oncol 2012;23: 1394-402.

35. Bradbury KE, Appleby PN, Key TJ. Fruit, vegetable, and fiber intake in relation to cancer risk: findings from the European prospective investigation into cancer and nutrition (EPIC). Am J Clin Nutr 2014;100 Suppl 1:394S-398S

36. Block G. Vitamin $C$ and cancer prevention: the epidemiologic evidence. Am J Clin Nutr 1991;53:270S-282S.

37. Byers T, Guerrero N. Epidemiologic evidence for vitamin C and vitamin E in cancer prevention. Am J Clin Nutr 1995;62:1385S-1392S.

38. Kirkland JB. Niacin and carcinogenesis. Nutr Cancer 2003;46:110-8.

39. Park SM, Li T, Wu S, Li WQ, Weinstock M, Qureshi AA, Cho E. Niacin intake and risk of skin cancer in US women and men. Int J Cancer 2017;140:2023-31.

40. Sun $N H$, Huang $X Z$, Wang SB, Li Y, Wang $L Y$, Wang $H C$, Zhang $C W$, Zhang C, Liu HP, Wang ZN. A dose-response meta-analysis reveals an association between vitamin B12 and colorectal cancer risk. Public Health Nutr 2016;19:1446-56.

41. Miranti EH, Stolzenberg-Solomon R, Weinstein SJ, Selhub J, Männistö S, Taylor PR, Freedman ND, Albanes D, Abnet CC, Murphy G. Low vitamin $\mathrm{B} 12$ increases risk of gastric cancer: a prospective study of one-carbon metabolism nutrients and risk of upper gastrointestinal tract cancer. Int J Cancer 2017;141:1120-9.

42. Cui LH, Quan ZY, Piao JM, Zhang $T$, Jiang $M H$, Shin $M H$, Choi JS. Plasma folate and vitamin B12 levels in patients with hepatocellular carcinoma. Int J Mol Sci 2016;17:E1032.

43. D'Elia L, Galletti F, Strazzullo P. Dietary salt intake and risk of gastric cancer. Cancer Treat Res 2014;159:83-95.

44. World Cancer Research Fund International. Preservation and Processing of Foods and the Risk of Cancer. London: World Cancer Research Fund International; 2018.

45. Hutschenreuther A, Birkenmeier G, Bigl M, Krohn K, Birkemeyer C. Glycerophosphoglycerol, beta-alanine, and pantothenic acid as metabolic companions of glycolytic activity and cell migration in breast cancer cell lines. Metabolites 2013;3:1084-101.

46. International Agency for Research on Cancer. Agents classified by the IARC monographs, vol 1-100 [Internet]. Lyon: International Agency for Research on Cancer; year [cited 2019 May 1]. Available from: https://monographs.iarc.fr/wp-content/uploads/2018/09/Class ificationsAlphaOrder.pdf.

47. World Cancer Research Fund International. Judging the Evidence. London: World Cancer Research Fund International; 2018.

48. Fuhrman $\mathrm{JH}$, Leville $\mathrm{K}$, inventors; Whole Foods Market, Inc., assignee. Methods for developing and conducting a nutritional treatment program. United States patent US 20080177572A1. 2008 Jul 24.

49. Katz DL, Njike VY, Rhee LQ, Reingold A, Ayoob KT. Performance characteristics of NuVal and the overall nutritional quality index (ONQI). Am J Clin Nutr 2010;91:1102S-1108S.

50. Guenther PM, Casavale KO, Reedy J, Kirkpatrick SI, Hiza HA, Kuczynski $\mathrm{KJ}$, Kahle LL, Krebs-Smith SM. Update of the healthy eating index: HEl-2010. J Acad Nutr Diet 2013;113:569-80.

51. Kim S, Haines PS, Siega-Riz AM, Popkin BM. The diet quality index-International (DQI-I) provides an effective tool for crossnational comparison of diet quality as illustrated by China and the United States. J Nutr 2003;133:3476-84. 